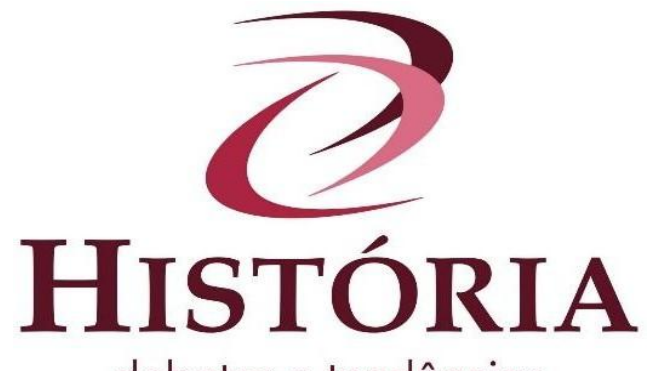

\title{
Iniciativas Escolares Polonesas - Polskie szkoly no Brasil e a atuação do consulado no pós-reunificação polonesa: discursos e negociações culturais e identitárias.
}

\section{Polish school initiatives - Polskie szkoty in Brazil and role of the consulate in polish post-reunification: speeches and cultural and identity negotiations.}

\author{
Polskie inicjatywy szkolne w Brazylii a rola konsulatu po zjednoczeniu Polski: \\ przemówienia i negocjacje kulturowo-tożsamościowe.
}

Fabiana Regina da Silva ${ }^{\mathrm{i}}$

\begin{abstract}
Resumo: O presente texto tem o objetivo de refletir sobre a atuação do consulado polonês como órgão oficial da comunidade de saída - pós-reunificação, sediado em Curitiba - PR e, assim, dos agentes consulares em relação às iniciativas escolares étnicas dos migrantes no Brasil, em suas organizações de sociedades de apoio particulares, comunitárias e confessionais, na primeira metade do século 20. Tais iniciativas eram permeadas por discursos e negociações entre a comunidade de saída, sob a emergência de construções nacionais e intenções de estabelecer colônias ultramarinas, e o contexto local. Nesta complexa rede de relações e negociações, as interferências consulares são efetivas em relação aos delineamentos educacionais escolares dos migrantes e descendentes e os objetivos destes espaços culturais e de poder.
\end{abstract}

Palavras-chave: migrantes poloneses. escolas étnicas polonesas. consulado polonês no Brasil.

\begin{abstract}
This text aims to reflect on the role of the polish consulate as an official organ of the outgoing community - post reunification, based in Curitiba - PR and, thus, of the consular agents in relation to the ethnic school initiatives of migrants in Brazil, in their organizations private, community and confessional, support societies in the first half of the $20^{\text {th }}$ century. Such initiatives were permeated by speeches and negotiations between the outgoing community, under the emergence of national constructions and intentions to establish overseas colonies, and the local context. In this complex network of relations and negotiations, consular interferences are effective in relation to the educational designs of migrants and descendants and the objectives of these cultural and power spaces.
\end{abstract}

Key-words: polish migrants, polish ethnic schools, polish consulate in Brazil.

Streszczenie: W kontekście procesów konstruowania i wyodrębniania się tożsamości narodowych w pierwszej połowie XX wieku, Niniejszy artykuł analizuje kulturowe, polityczne i religijne powiązania, które przenikały inicjatywy edukacyjne $\mathrm{w}$ etnicznych 
społecznościach Polonii w Brazylii. Jednocześnie zwraca uwagę na rolę konsularnych działaczy w projektowaniu i konstruowaniu dyskursów oraz działań na rzecz budowy ducha narodowego jako wspólnoty wyobrażonej.

Słowa kluczowe: polscy migranci, polskie szkoły etniczne, Konsulat Generalny RP w Brazylii.

\section{Introdução}

As comunidades étnicas no contexto brasileiro das migrações históricas europeias dos séculos dezenove e vinte, organizadas a partir da formação de núcleos urbanos e rurais, conforme vem se destacando em trabalhos acadêmicos, principalmente no campo da História da Educação, caracterizaram-se também pela organização de processos educacionais escolares étnicos definidos a partir de fronteiras étnico-culturais dos migrantes. Estes processos educacionais escolares étnicos são articulados a partir da organização de sociedades escolares étnicas - entidades comunitárias e confessionais/educacionais - espaços de cultura e poder e por isso também de articulação política, porém, não desvinculados de suas comunidades de saída ou, dos locais de emigração no continente europeu.

No caso dos migrantes poloneses, a partir da primeira metade do século vinte, a mediação entre comunidade de saída e núcleos de migrantes no exterior e, neste caso, no Brasil, ocorre mais intensivamente através do órgão oficial - consulado e dos agentes consulares como presenças efetivas na comunidade receptora. Possibilidade efetiva a partir da condição da reunificação polonesa durante a Primeira Guerra Mundial, o reconhecimento oficial desta no contexto internacional, e a emergência da Segunda República Polonesa. Antes da reunificação, a condição da Polônia tripartida desde o século dezoito entre Prússia, Àustria e Rússia, não lhes propiciava sequer possibilidade de vinculação cidadã à Polônia, então inexistente. Isso não significou, entretanto, a inexistência de vinculação cultural e étnica em perspectiva de diáspora ${ }^{i i}$.

Após a reunificação, com a condição de vinculação oficial e recuperação da autoestima entre os migrantes, somando-se à presença e atuação consular, foi marcante o fortalecimento das sociabilidades e a influência de outras entidades polonesas, sobretudo, aquelas de cunho confessional. Embora entre as sociabilidades, as instituições educacionais comunitárias e confessionais já se fizessem presentes no Brasil desde o século dezenove e mais acentuadamente no início do século vinte, e estivessem articuladas a orientações de órgãos poloneses não oficiais, por vezes subversivos nos distintos domínios, estas entidades fortaleceram-se com a nova realidade cultural e política. 
De modo geral, com a instalação dos consulados entre os migrantes, articulados em motivações como a emergência de nações e de identidades nacionais e de intenções colonizadoras europeias voltadas para o estabelecimento de colônias ultramarinas, tais órgãos e os agentes consulares passaram a representar uma espécie de "centro de referência" para questões burocráticas e, em alguma medida, culturais, para as comunidades de migrantes europeus espalhadas pelo Brasil. Isso é observado por pesquisadores de distintos grupos migrantes em suas distinções étnico-culturais e de origem, entre eles, os poloneses, alemães e italianos.

Em meio à realidade de um volumoso contingente de migrantes saídos de portos europeus no período aqui delimitado, quando em condições, os países de origem passaram a preocupar-se no sentido de estabelecer algumas estratégias voltadas para a não desvinculação cultural, linguística e até mesmo política de seus emigrantes. Tais preocupações são vistas pelos estudos contemporâneos tanto no sentido de não os deixar desamparados, reconhecendo as dificuldades da nova realidade, quanto no sentido de não desvinculação ampla, conforme mencionamos acima, mas também, de garantia de direitos, amparo civil e burocrático, participação política e mobilidade social em relação à nova residência, de formação de redes de apoio, e, até mesmo, de possibilidades de retorno e de intenções de estabelecimento de colônias ultramarinas.

Assim, evidenciamos neste texto, que na complexa rede de relações e negociações do contexto brasileiro, os agentes consulares poloneses estiveram atuando de maneira atenta aos objetivos da Segunda República em relação às entidades comunitárias e/ou confessionais/educacionais, às questões e os delineamentos escolares dos migrantes e seus descendentes, dados nestes espaços culturais, políticos e de poder, discursivamente ligados à comunidade de saída. O segundo aspecto reside na inferência de que a atuação culturalmente marcante destas entidades oficiais no período delimitado é, em certa medida, estancada a partir da realidade e efetividade da política de nacionalização, durante o período histórico brasileiro conhecido como Estado Novo (1937-1945), seu perfil de centralização de poder e de construção nacionalista, somado ao início da Segunda Guerra Mundial.

Para tanto, analisamos inicialmente e de forma breve, o contexto da formação das comunidades étnicas polonesas, situando a formação das instituições escolares étnicas e o processo escolar étnico. Em um segundo momento, focalizamos nosso objetivo principal, a relação estabelecida entre os órgãos consulares e seus agentes em relação aos processos educacionais escolares articulados em tais comunidades étnicas e as respectivas 
sociedades escolares, evidenciando discursos e negociações circulantes, objetivos culturais e políticos nas distintas interfaces.

No intuito de clarificar como estas questões foram sendo urdidas, ressaltamos que a discussão está situada no campo da História Cultural e conversa com algumas reflexões desenvolvidas por Silva (2019) ${ }^{\mathrm{iii}}$ em relação as sociedades polonesas no Brasil, pósreunificação polonesa. Entre as fontes utilizadas para análise, considerando a delimitação anunciada pela pesquisa, destacamos aquilo que foi produzido no contexto das relações sociais, públicas e oficiais, nacionais e internacionais, sejam estes: documentos oficiais, documentos públicos e privados, cartas, memoriais, livros e jornais, fotografias, fontes autobiográficas e escrituras ordinárias de ex-professores, intelectuais e agentes étnicos, políticos e religiosos, aqui utilizadas como fontes, assim, não a partir do olhar teóricometodológico de análise do campo das narrativas autobiográficas. Entre as escrituras ordinárias estão os manuscritos de Ruy Christovam Wachowicz.

Para Daniel Fabre (1993), as escritas ordinárias são aquelas feitas por sujeitos comuns, os quais não se preocupam com a qualidade daqueles escritos com intencionalidade de "virar obra". Podem ser bilhetes, diários, anotações, entre outros, e conter resquícios e indícios do vivido. Já as fontes (Auto)biográficas são constituídas por "histórias de vida, relatos orais, fotos, diários, autobiografias, biografias, cartas, memoriais, entrevistas, escritas escolares e videográficas" (DELORY-MOMBERGER, 2008, p.5).

No entanto, não temos a pretensão de afirmar uma narrativa homogeneizante de relações entre sociedades escolares e agentes consulares, uma vez que, não se pode desconsiderar a pluralidade de realidades e variáveis envolvidas nestes processos sociais. Assim, traremos alguns aspectos que se sobressaem nas pesquisas que experienciamos como construção, em nosso processo formativo de pós-graduação/mestrado e doutorado e, naquelas com as quais temos "conversado" neste percurso formativo, na prática da intersubjetividade $^{\text {iv }}$ a partir de Jörn Rüsen (2015).

\section{Migrantes poloneses no Brasil e a formação de sociedades escolares étnicas}

Enquanto identificação étnicav ${ }^{\mathrm{v}}$, compreendida a partir das fronteiras (BARTH, 1969), aqui considerada como mais abrangente que outras possibilidades de análise, concentrações de migrantes poloneses e seus descendentes em termos quantitativos, 
encaminharam-se para o Brasil meridional, estando em primeira colocação o estado do Paraná e, em seguida, os estados de Santa Catarina e Rio Grande do Sul. No entanto, tais migrantes se espalharam para outros países no mundo e pelos distintos estados brasileiros nos séculos dezenove e vinte, e em ambos, atingiram contingentes bastante significativos.

No Paraná a migração polonesa se fortaleceu como referência migrante deste grupo após os "peregrinos" - inicialmente instalados em Santa Catarina, terem migrado para este estado a partir de 1873. Malczewski (2008, p. 38) ressalta, que "graças aos empenhos do Pe. Antonio Zielinski e de Sebastião Edmundo Wós Saporski, 32 famílias polonesas (164 pessoas) estabeleceram-se em Pilarzinho, na região de Curitiba". Ou seja, boa parte daquele primeiro grupo que havia chegado da Alta Silésia no porto de Itajaí, a bordo do navio "Vitória" e se assentado na colônia Brusque, era então, os "peregrinos" no Paraná (GLUCHOWSKI, 2005). Aos poucos, outros grupos chegaram ao PR e SC e restante do Brasil.

No RS, concentram-se mais nas regiões Norte e Missões, porém, as primeiras levas chegaram à região da Serra Gaúcha a partir de 1875, encontrando os migrantes italianos já instalados naquela região. Com a chegada de outros grupos da migração polonesa, em seguida organizaram-se outros destinos, entre eles, a capital do estado, a cidade portuária de Rio Grande, e as terras das regiões Norte e Missões, estas, ainda "disponíveis" do ponto de vista do projeto de colonização oficial e depois, das empresas colonizadoras. No norte do estado, entre os principais destinos destes migrantes, podemos destacar os municípios de Guarani das Missões, Áurea e Erechim.

Sob o império e depois sob a república oligárquica, os imigrantes viam-se, abandonados pelo estado e as políticas públicas e, ao mesmo tempo, livres para se organizarem sócio-culturalmente. Pois, conforme Wachowicz (s/ano, p. 5) "vi "Os imigrantes poloneses, uma vez estabelecidos em suas colônias ou nos centros urbanos, deparavam-se com sérios problemas: não havia escolas para seus filhos". Para o autor, "Como poderia o governo, que ainda lutava com falta de professores competentes para as próprias crianças brasileiras, proporcionar professores para os estrangeiros?”. De acordo com Wachowicz (1970, p. 13) $)^{\mathrm{vii}}$,

Essa falta de recursos ou o próprio desconhecimento/do problema por parte do governo, levou os imigrantes a procurarem resolver seus próprios problemas. Os colonos, eles mesmos em parte analfabetos, esforçaram-se para proporcionar a seus filhos os conhecimentos das primeiras letras e de aritmética. Tal situação levou as comunidades polonesas a procurarem uma solução para o problema. A encontrada pelos colonos foi a da Escola Sociedade, que reunia numa só instituição o útil ao agradável. Esta foi instituição escolar-recreativa, é a primeira 
manifestação/ coletiva da aculturação do imigrante polonês no Brasil. Os mais competentes criaram para estas escolas, que funcionavam em língua polonesa, suas próprias cartilhas e material escolar necessário.

Com cartilhas próprias, poderiam dar garantia da continuidade do uso cotidiano da língua polonesa. Para Renk (2014, p. 72), “A língua materna era o elemento essencial de manutenção da identidade étnica, pois ela expressa a cultura e as formas de ver o mundo", um sistema simbólico e de representações (CHARTIER, 1990). Conforme aponta um dos pesquisadores destas organizações socioculturais étnicas, o professor Lúcio Kreutz (2000, p. 59), "Para favorecer a dinâmica comunitária nos núcleos de imigrantes, organizava-se um conjunto de 80 a 100 famílias, aproximadamente, com suas pequenas propriedades, em torno de um centro".

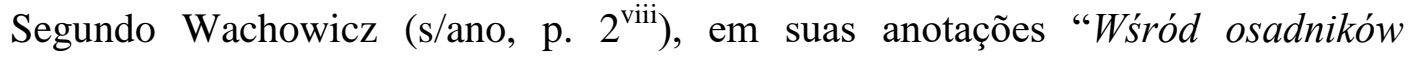
polskich" - "Entre colonos poloneses" (tradução nossa), onde constam trechos de falas do Bispo polonês no Brasil - Teodor Kubina, este ressalta que a possibilidade da liberdade encontrada no Brasil facilitou a preservação do "espírito polonês" para moldar a vida, a construção de uma "Nova Polônia", complementa ainda: "antes que a Polônia existisse como livre e soberana: construíram igrejas próprias polonesas, escolas, sociedades, casas do povo, conservaram seus costumes e tradições, conservaram a fé e o idioma". O Bispo destaca, no entanto, a necessidade de se investir na educação e na sua padronização e uniformidade, seu planejamento, destituindo a diversidade de orientações, tornando-a somente católica, justifica que ao saírem da Polônia católica, deveriam carregar consigo e fazer jus a esta herança da pátria.

Em meio ao cenário exposto, não podemos nos desaperceber das questões culturais e identitárias envolvidas, decisivas para se tomar as decisões e atitudes mencionadas em relação à formação de comunidades, grupos e sociedades escolares étnicas, reconhecendo em tais formações, processos culturais e identitários relacionais, impulsionados na percepção e manutenção da diferença (CUCHE, 2002) e (HALL, 2006) e nas fronteiras da etnicidade (BARTH, 1998).

Para Cuche (2002, p. 238) as culturas são passíveis de "trabalho", assim, não se tratam de processos descontínuos. Estes processos contínuos permeiam o estabelecimento de fronteiras e identidades, onde "As características que são levadas em consideração não são a soma das diferenças "objetivas", mas somente aquelas que os próprios atores consideram significantes" (BARTH, 2011, p. 195). Neste escopo, “A identidade é irrevogavelmente uma questão histórica" (HALL, 2013, p. 33), dada na diferença. 
Malikoski \& Luchese (2017, p. 88) analisam o processo de organização e estruturação das escolas polonesas no Rio Grande do Sul entre 1875 a 1939. Conforme os autores, neste período "foram priorizados o ensino elementar e a manutenção de especificidades étnicas, como língua, religiosidade e valores culturais poloneses", por isso, afirmam que "a cultura étnica foi um elemento importante na estruturação de processos associativos e comunitários da imigração polonesa, que promoveu a estruturação de escolas na maior parte dos seus núcleos coloniais". Essa percepção também encontra ressonância em outros estados brasileiros.

Neste escopo, conforme Malczewski \& Wachowicz (2000, p. 82-84) “Um dos primeiros poloneses a se estabelecer no Paraná foi Jerônimo Durski ${ }^{\text {ix }}$, que veio ao Brasil ainda em 1851", tornou-se professor de língua polonesa e foi reconhecido, conforme ressaltam os autores, como o "pai das escolas polonesas no Brasil", fundou a primeira Sociedade Escolar na colônia de Orleans em 1876, e "preparou a primeira Cartilha para as escolas polonesas no Brasil em língua polonesa e portuguesa, publicada em 1893" (MALCZEWSKI, WACHOWICZ, 2000, p. 82-84).

A partir daí, aos poucos foram evidenciando-se outras organizações em núcleos de migrantes pelos estados brasileiros, principalmente após a reunificação polonesa.

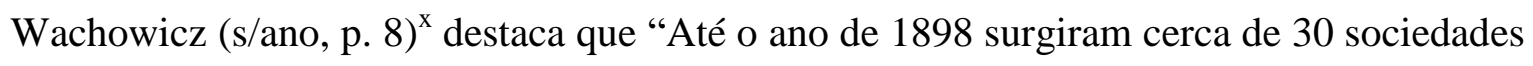
mas, fundadas sem planificação e muito fracas, não tinham maior expressão". Conforme o autor, “Tinham por finalidade a manutenção de escola, além da comemoração de datas nacionais, organização de apresentações teatrais e com menor frequência a manutenção de uma biblioteca e atividade extra-escolar".

O fortalecimento das sociedades já existentes e a criação de outras nos distintos estados brasileiros foi sendo impulsionado por fatores como a chegada de congregações religiosas e de intelectuais e agentes étnicos ${ }^{\mathrm{xi}}$. $\mathrm{O}$ surgimento de novas sociedades esteve acompanhado pelo crescimento da imprensa étnica que se mostrou bastante presente em distintas regiões brasileiras. Ainda, conforme Wachowicz (2010), a imprensa migrante, colocou-se em intercâmbio com a imprensa na Polônia. Embora muitas delas tenham sido formalizadas somente após a independência, suas atuações ligadas à etnicidade, já eram realidade.

Nos educandários comunitários, a prática docente era realizada por professores particulares, pagos pela comunidade e/ou os pais dos estudantes, assim como, as demais despesas escolares e de estrutura. Com a reunificação polonesa surgem outras demandas ao ambiente educacional escolar, assim, mesmo com as iniciativas próprias, há novas 
possibilidades em relação aos aspectos financeiros e operacionais, articuladas a órgãos oficiais como o consulado.

\section{As iniciativas escolares étnicas polonesas - polskie szkoły no Brasil e as intervenções consulares no pós-reunificação polonesa.}

Embora orientações mais gerais desde a Polônia tripartida e das associações lá existentes já estivessem presentes nas sociabilidades dos migrantes, antes da reunificação as sociedades escolares étnicas polonesas não estavam articuladas a uma orientação efetiva e com unicidade e continuidade de atuação. Dentre as orientações desde a Polônia tripartida, algumas destas associações atuando de forma subversiva nos distintos domínios, destacamos as entidades religiosas vicentinas e lazaristas, Sagrada Família e Caridade - opostas à igreja ortodoxa russa, a Escola Popular (progressista e anti-clerical Łódź), o Departamento de Educação em Lwów e os chamados "cônsules austríacos", ligados à Sociedade Geográfica e Comercial, com sede em Lwów ${ }^{x i i}$ - presentes entre os migrantes no Brasil desde o final do século dezenove, etnicamente poloneses e membros da organização burocrática na porção do domínio austro-húngaro.

Para estas instâncias de orientação das sociabilidades, principalmente órgãos oficiais e laicos, a inexistência do estado unificado, conforme destaca boa parte da literatura existente, não lhes dava condições de plena ação, ação coordenada e desenvolvimento contínuo, considerando que muitas vezes faltava-lhes, entre outras questões, a liberdade. Então, mesmo que questões culturais e identitárias estivessem presentes entre os migrantes e motivassem à existência destas iniciativas, cada lugar ou núcleo tinha sua própria dinâmica e, por vezes, desvelavam-se bastante destoantes.

Com a reunificação da Polônia em 1918, durante a Primeira Guerra Mundial, e o posterior reconhecimento legal e político da Polônia restituída, por países como o Brasil, criam-se condições para, em 1920, instalar-se em Curitiba - PR o órgão oficial consulado polonês, tendo como primeiro cônsul o Sr. Kazimierz Gluchowski, este, além de diplomata, jornalista e intelectual, era um ativista social. Anteriormente, Gluchowski estivera em outros países da Europa e da América, instalando-se no Brasil a partir de 1919.

Por parte das instituições representativas oficiais do estado da Polônia reunificada, voltando-se para os objetivos como a construção do estado-nação, organizaram-se levantamentos internos como o Censo e, em relação aos migrantes da diáspora, houve o imediato interesse de que fizessem o reconhecimento legal. No Brasil, isso foi motivo de 
propaganda e de empenho dos órgãos governamentais como o consulado, assim, buscando a efetiva divulgação nos mais remotos locais do país, porém, em muitos casos, questões de distância, saúde, de perfil do trabalho consular, econômicas e até relacionadas a fatores psicológicos e esquecimentos intencionais, foram impossibilidades deste processo.

Estas questões relacionadas às dificuldades acima mencionadas, também são evidenciadas por Iotti (2010, p.98) em relação ao trabalho dos cônsules italianos entre os migrantes no Brasil e a relação com a Itália recém-unificada. Este trabalho, na maioria das vezes respondeu por uma grande extensão territorial e o relacionamento com os imigrantes se deu de forma rápida e superficial. A autora ressalta ainda, as diferenças econômicas, sociais e culturais entre os envolvidos e observa que os cônsules, muitas vezes, tratavam os migrantes com indiferença e má vontade, pois, os reconheciam como camponeses miseráveis e ignorantes, enquanto eles se destacavam por suas capacidades na carreira diplomática e pertenciam às altas camadas sociais da sociedade italiana. Assim como no caso dos poloneses, a autora, também identificou as dificuldades em relação às diferenças culturais das distintas regiões unificadas.

No entanto, "Todo sistema político surge ligado a um sistema de valores e representações" (CUCHE, 2002, p. 2016), neste caso, perpassados por uma trajetória de dominação, imposições culturais e dos nacionalismos das políticas imperialistas dominantes, a postura tomada pela Segunda República desvelou-se bastante decidida na imaginação cultural da nação. Esta, conforme Hobsbawm (2011) aponta para uma construção verticalizada. Piłsudki revelou-se com posicionamento centralizador e autoritário, amparado pela constituição adotada em 1926, cuja dimensão textual aos poucos foi sendo alterada. Esta posição e constituição, a "Constituição Polaca", foi adotada no Brasil durante a ditadura do Estado Novo de Vargas, a partir de 1937.

Dentre as ideias propagadas por políticos e por intelectuais nacionalistas poloneses pós-reunificação, estavam prospecções imperialistas a partir de políticas de colonização ultramarina em países como: Peru, Argentina, Bolívia e Brasil, a partir de ações de companhias privadas com o apoio do Estado, como a Liga Morska i Kolonialna (Liga Marítima e Colonial) (MAZUREK, 2016). A Liga buscava áreas para tal objetivo na América do Sul e também na África, e entendia que as populações da diáspora facilitariam o processo. A formalização dessas colônias seria também uma forma de solucionar problemas internos como os debates sobre a questão da terra (movimentos 
camponeses) e fortalecer-se no cenário europeu e internacional, inserindo-se em projetos neocolonialistas.

Com a desintegração dos antigos impérios e de suas políticas imperialistas e a reunificação de estados como a Polônia, Hall (2006, p. 93-94) destaca que "Esses novos aspirantes ao status de "nação" tentam construir estados que sejam unificados tanto em termos étnicos quanto religiosos e criar entidades políticas em torno de identidades culturais homogêneas". Então, como na imaginação da nação proposta por Anderson (2008), questões étnicas e culturais foram colocadas em destaque, retomando a arqueologia da existência de diferentes tribos que foram unificadas nos primórdios, narrativas presentes nas escritas da elite intelectual polonesa em tons românticos e que evidenciam reivindicações de sua anterioridade, unidade e legitimidade desde tempos remotos, na pretensão de afirmar sua história milenar, uma ideia de recuperação e de reafirmação das raízes culturais, da cultura nacional, perspectiva essencialista.

A pretensa gradual unificação e as perspectivas de nações modulares constavam em seus conteúdos o entendimento de etnia como uma construção cultural fundacional. Para Hall (2006, p. 62), “A etnia é o termo que utilizamos para nos referirmos às características culturais - língua, religião, costume, tradições, sentimento de "lugar" - que são partilhadas por um povo", e embora seu uso seja tentador, foi aos poucos sendo desconstruída, "essa crença acaba, no mundo moderno, por ser um mito", pois, a Europa Ocidental não tem qualquer nação que seja composta de apenas um único povo, uma única cultura ou etnia, nem mesmo neste período.

Já em relação ao sistema educacional, não havia condições efetivas de se ter um sistema de imediato, e com amplo acesso para uma população cuja porcentagem de analfabetos era altíssima e com diferenças nos mais amplos sentidos. Então, membros dos movimentos camponeses, populares e nacionalistas, além de serviços sociais, desenvolveram um trabalho de apoio nesse sentido. Conforme Brainerd (2001, p. 21, tradução nossa), a fundação e o desenvolvimento inicial do serviço social na Polônia está intimamente ligado à criação de uma identidade nacional. Ressalta, que "Dentro deste modelo de trabalho social, os trabalhadores sociais freqüentemente assumem o papel de educadores".

De certa forma, emergiu um ambiente interno que, de forma geral, tentava colocar tudo sob a mira do panóptico ${ }^{\text {xiii }}$, cujo direcionamento foi conduzido por elites aristocráticas e por intelectuais e religiosos, mas, que também atuavam a frente os trabalhadores sociais, membros dos movimentos camponeses, populares. Para Hall (2006, 
p. 61), "Em vez de pensar as culturas nacionais como unificadas, deveríamos pensá-las como constituindo um dispositivo discursivo que representa a diferença como unidade ou identidade". Isso porque, "Elas são atravessadas por profundas divisões e diferenças internas".

Conforme a narrativa autobiográfica do polonês Zigmunt Bauman $\left(2005\right.$, p. $\left.33^{\text {xiv }}\right)$, "Na Polônia da era da construção nacional, as crianças costumavam ser treinadas a dar as seguintes respostas a perguntas sobre identidade: Quem é você? Um pequeno polonês. Qual é o seu signo? A Águia Branca”. Ou seja, colocam-se os discursos ideológicoessencialistas em um contexto diverso, em que muitos buscavam apenas "ser polonês por livre adesão" e diferença e não por um tortuoso e coercitivo caminho "em nome da identidade exclusiva" (CUCHE, 2002, p. 195), após toda a imposição cultural por parte dos invasores, vivenciada antes da reunificação.

Para Bauman (2005, p. 25), "perguntar "quem você é" só faz sentido se você acredita que possa ser outra coisa além de você mesmo; só se você tem uma escolha, e só se o que você escolhe depende de você". Segundo o autor, isso só pode acontecer "se você tem de fazer alguma coisa para que a escolha seja "real" e se sustente", não meramente imposta e esvaziada de sentido próprio.

A partir desta contextualização pós-reunificação, ressaltamos que as comunidades migrantes na diáspora, são ligadas à Polônia reunificada em "elementos rastreadores básicos" (HALL, 2013, p. 35), e que em meio à diversidade que os perpassa e em convivência com múltiplas referências culturais, passam a receber por parte dos órgãos oficiais, desejáveis alinhamentos de aspectos culturais e identitários. No entanto, “o indivíduo que faz parte de várias culturas fabrica sua própria identidade fazendo uma síntese original a partir destes diferentes materiais" (CUCHE, 2002, p. 193), elementos "singularmente combinados em distintas configurações em cada lugar" (HALL, 2013, p. $35)$.

O cônsul Gluchowski, bastante presente e atuante, no intuito de mapear a situação da migração polonesa no Brasil e suas iniciativas associativas étnicas, principalmente as escolares, realizou itinerários de viagem e pesquisa por distintos locais, coletando dados e articulando lideranças e ações, levantando potencialidades e necessidades, mas, acima de tudo, incentivando a ampliação das possibilidades de sociabilidade e de educação escolar étnica comunitária e confessional. Em relação à educação escolar os relatos de Gluchowski (2005) mostram sua visão de precariedade das organizações e do perfil de 
ensino das escolas, com professores leigos e instalações e materiais improvisados, muitas delas, paralisadas durante a I Guerra Mundial.

As mencionadas instâncias de orientação das sociabilidades dos migrantes, existentes na Polônia tripartida e sediadas principalmente na Galícia austríaca - porção do domínio Austro-Húngaro, foram praticamente paralisadas durante o conflito mundial, voltando-se exclusivamente a unir forças para retomar a independência, captando homens e recursos, inclusive entre os emigrados. Assim, a reunificação da Polônia significou muito para os poloneses na diáspora, para a etnicidade, uma retomada para as sociabilidades e expectativas internas e externas.

Nas condições discutidas até aqui e, a partir de objetivos nacionalistas e de interesses múltiplos da Segunda República, intelectuais poloneses foram incentivados a migrar e a realizar na diáspora, um trabalho voltado para tais objetivos e além do consulado, representando o cristianismo católico, os religiosos vicentinos estabeleceram a Vice-Província Polonesa no Brasil (1920) ligada a Província da Cracóvia. Os vicentinos, a partir de então, empenharam-se em fortalecer as ações educacionais escolares clericais, no intuito de frear o avanço do "anticlericalismo" entre os migrantes.

Foi neste contexto que as tentativas de unificação da atuação das sociedades polonesas, principalmente as escolares, objetivo não alcançado em tentativas anteriores, foram novamente recolocadas no cenário. Porém, conforme Wachowicz (s/ano, p. 8), a partir do ano 1900 "nota-se uma clara divisão da comunidade em dois blocos", a seguir:

- Progressistas anticlericais - migrantes e intelectuais de formação esquerdista, muitos deles emigrados no pós-revolução de 1905, políticos ligados ao Partido Socialista Polonês 1892 - esquerda progressista, lideranças étnicas, professores comunitários, nacionalistas, profissionais liberais, artistas, membros do Grupo de Lwów, membros da maçonaria, entre outros.

- Clericais - religiosos Vicentinos e Verbitas, religiosas, membros do Grupo de Lwów, intelectuais, professores comunitários e paroquiais, lideranças étnicas, nacionalistas, membros da maçonaria, entre outros.

Essa divisão era claramente perceptível principalmente em Curitiba e arredores, considerando o contingente numeroso de migrantes poloneses congregados, intelectuais e agentes étnicos, e a centralidade das ações. Assim, pensadas por grupos de distintas posições culturais e ideológicas - católicos clericais e progressistas anticlericais, mas, que em ambos os lados estavam também posturas nacionalistas e esquerdistas e "elementos culturais rastreadores básicos", e na impossibilidade de unirem-se sob uma única 
organização, foram oficializadas a partir de 1920, duas uniões das sociedades - instâncias de orientação das sociabilidades, entre elas as escolares, consideradas prioritárias. Estas uniões receberam o nome de Associação Kultura e Associação Oświata ${ }^{x v}$ (Educação) - a primeira de orientação progressista e a segunda, clerical (SILVA, 2019).

Conforme Silva (2019), estas instâncias de orientação das sociabilidades centralizaram-se no Paraná por, entre outros motivos, o estado possuir a maior comunidade de migrantes poloneses e descendentes no Brasil. As uniões Kultura e Oświata congregam e orientam, durante a primeira metade do século vinte, sociedades escolares, culturais, recreativas, religiosas e esportivas. Ambas atuam na imprensa étnica e pedagógica, na produção de materiais de notícias e informes, nas atividades sociais, religiosas, educacionais e culturais e uso da língua, articulando-se a polonidade(s) (SILVA, 2019).

Junto dessas ações e em perspectiva de apoio e fortalecimento a tais organizações sociais, há presença efetiva do consulado. A atuação do cônsul Gluchowski se articulou em termos culturais e nacionalistas e em posicionamento progressista, mas, não se opunha à existência dos mencionados grupos distintos, acreditando que a disputa entre ambos poderia ser proveitosa e fomentar o amplo desenvolvimento social, educacional e cultural. Sob este novo "ânimo", as sociabilidades já existentes, porém paralisadas durante a guerra, foram revitalizadas e são criadas muitas outras, principalmente, voltadas para a educação escolar.

Esta fase trouxe autoestima aos poloneses migrantes e vitalidade aos processos culturais e identitários articulados nas sociabilidades, nos distintos estados brasileiros. Para Renk (2009, p. 52), as sociedades eram um importante espaço de manutenção da identidade étnica. Esta fase é considerada a mais fértil dentro da primeira das três etapas da construção da identidade polonesa no Brasil, desenvolvidas por Siuda-Ambroziak (2017).

Percebemos um olhar especial do consulado para a reorganização da educação escolar a partir do que ressalta Gluchowski (2005, p. 177):

\footnotetext{
A ação que foi iniciada em 1920 seguiu a seguinte linha: Antes de mais nada, era preciso criar um quadro dentro do qual pudesse encerrar-se o trabalho no campo da reforma escolar, um quadro organizativo que reunisse as sociedades, associações e pessoas que trabalhavam nessa área. Simultaneamente era preciso proceder a um esforço para reorganizar o magistério, ou para associá-lo, eliminando os elementos indesejáveis, formando-se novas pessoas, elevando o seu nível cívico, moral e profissional. [...] havia a questão dos manuais escolares, dos programas, das bibliotecas e da educação extra-escolar, dos contatos com a pátria de origem, etc.
} 
Malikoski (2014, p. 65) destaca que "É nesse tempo, de uma Polônia independente, que haverá um fluxo maior de professores e educadores poloneses para o Brasil com o objetivo de melhorar o processo de ensino étnico da imigração com acompanhamento oficial”. Nesse sentido, "Uma das primeiras iniciativas foi trazer da Polônia uma equipe de professores profissionais para atuarem na organização do ensino". No entendimento da construção da polonidade, dentre as sociabilidades étnicas, a escola polonesa teria que ser efetiva, atuante, com ensino contínuo durante o ano, com práticas escolares em língua polonesa e estudos sobre cultura e história da Polônia, questões vistas como imprescindíveis aos processos culturais das novas gerações (SILVA, 2019).

No entanto, a "equipe" que fez este "reforço", efetivando ações como formações aos professores e auxílio na organização das sociedades, buscando meios de superar as condições de ensino precárias e em baixo nível, conforme destacado pelo cônsul Gluchowski (2005), não possuía um número muito substancial (SILVA, 2019). Conforme Malikoski (2014, p. 65), "De acordo com a relação dos Professores poloneses do consulado em Curitiba, no ano de 1937, o número desses instrutores era de seis". Mesmo sendo um importante estímulo, não supriu a carência das comunidades espalhadas pelo país, tendo em vista outro dificultador: o fato de que na I Guerra Mundial, membros como lideranças e intelectuais étnicos, entre eles alguns professores com boa formação, haviam partido como voluntários para a França ou para a Galícia e muitos não retornaram (SILVA, 2019). Assim, a carência de formação para atuar nas escolas era uma das preocupações.

O trabalho destes formadores era financiado pelo governo polonês, no entanto, desde que cumprissem os critérios e exigências estabelecidas, entre estes, estavam critérios de atuação e moralidade, incentivo a posicionamentos nacionalistas e a disseminação da cultura imaginariamente polonesa, no sentido de Anderson (2008).

A função da "equipe" esteve mais voltada à mediação e orientação geral das atividades, articulação de formações e incentivo para que estudantes se tornassem novos professores. Buscavam uma espécie de "profisssionalização" do professorado, pois, muitos daqueles em atuação não possuíam formação específica e, muitas vezes, nem mesmo o ensino secundário. Em relação aos objetivos ligados aos processos educacionais escolares, Malikoski (2014, p. 65) ressalta que "A atividade desses instrutores estava voltada para a orientação pedagógica e à organização de cursos de aperfeiçoamento para docentes das escolas étnicas polonesas". 
Em relação às sociedades escolares, outro ponto a ser considerado é o fato de que o aumento da estima dos migrantes com a reunificação não significou o aumento de suas possibilidades de financiar a manutenção das sociedades e dos profissionais ligados a estas, então, expandir a rede de escolas étnicas exigia ter certo apoio financeiro da Polônia. Isso tudo, vai aos poucos gerando condições e meios de controle e cobrança por parte de instituições oficiais polonesas, entre elas o consulado, que precisavam contar com apoios locais.

Assim, a criação de organizações amplas como instâncias de disseminação de orientações era uma boa estratégia para tentar minimizar as dificuldades encontradas e potencializar a perseguição aos objetivos delineados a partir da reunificação e da oficialização da Kultura (1920) e da Oświata (1922). Voltando-se para estes objetivos, organizaram-se cursos de formação pautados em uma proposta de educação desde a Polônia, mas, também, em diálogo com os contextos locais. Estes cursos tinham edições anuais em períodos de férias e eram compartilhados por membros de posicionamentos distintos (clericais e anticlericais), pois, além da exigência oficial, ambos estavam preocupados com seu aperfeiçoamento, considerando que havia certa concorrência entre instituições de ensino católicas e progressistas.

Além do apoio financeiro, outras providências foram tomadas pelo o consulado: o envio de livros e materiais didáticos da Polônia e doações pessoais de acervos - realizadas até mesmo pelo próprio cônsul, a ampliação da imprensa/jornais, revistas, almanaques, calendários, fundação de editoras próprias, livros didáticos e bibliotecas, Manuais Escolares e Cartilhas. Ampliar a capacidade pedagógica e estrutural das escolas paroquiais e comunitárias, também era uma forma de atrair novos estudantes.

Isso tudo, no entendimento dos órgãos oficiais, possibilitava ampliar a circulação de ideias e representações, articulando-se às referências culturais nacionalistas - estudo da história da Polônia, religiosidade e proficuidade da língua. Além disso, projetavam a formação de uma camada intelectualizada, para tanto, conquistaram objetivos como a implementação do ensino secundário no PR e no RS, inserção política, desenvolvimento de empresas e comércio étnico, profissionais liberais, criação de associações de professores e cursos de formação com material próprio, bibliotecas locais e volantes, professores locais e volantes e Grupos de juventudes.

Conforme Bourdieu (2007, p. 222) “inúmeras características nacionais da atividade intelectual devem ser referidas às tradições dos sistemas escolares cuja especificidade deriva de uma história nacional particular, e, sobretudo de sua história específica no interior 
desta história". Estas histórias específicas nacionais são enquadramentos discursivos que aos poucos são colocados em circulação pela Segunda República. Esta relação entre o consulado e as sociedades escolares era efetiva, conforme percebemos na figura 1 , o ofício assinado pelo cônsul Gluchowski, enviado pelo consulado à Francizek Hanas, liderança étnica, professor e presidente de uma sociedade étnica polonesa de Guarani das MissõesRS, tratava de questões como a adesão à associação nacional polaca e a gestão cultural desta.

Figura 1 - Ofício do cônsul Gluchowski à sociedade de Guarani das Missões-RS/ Curitiba PR, junho de 1921.

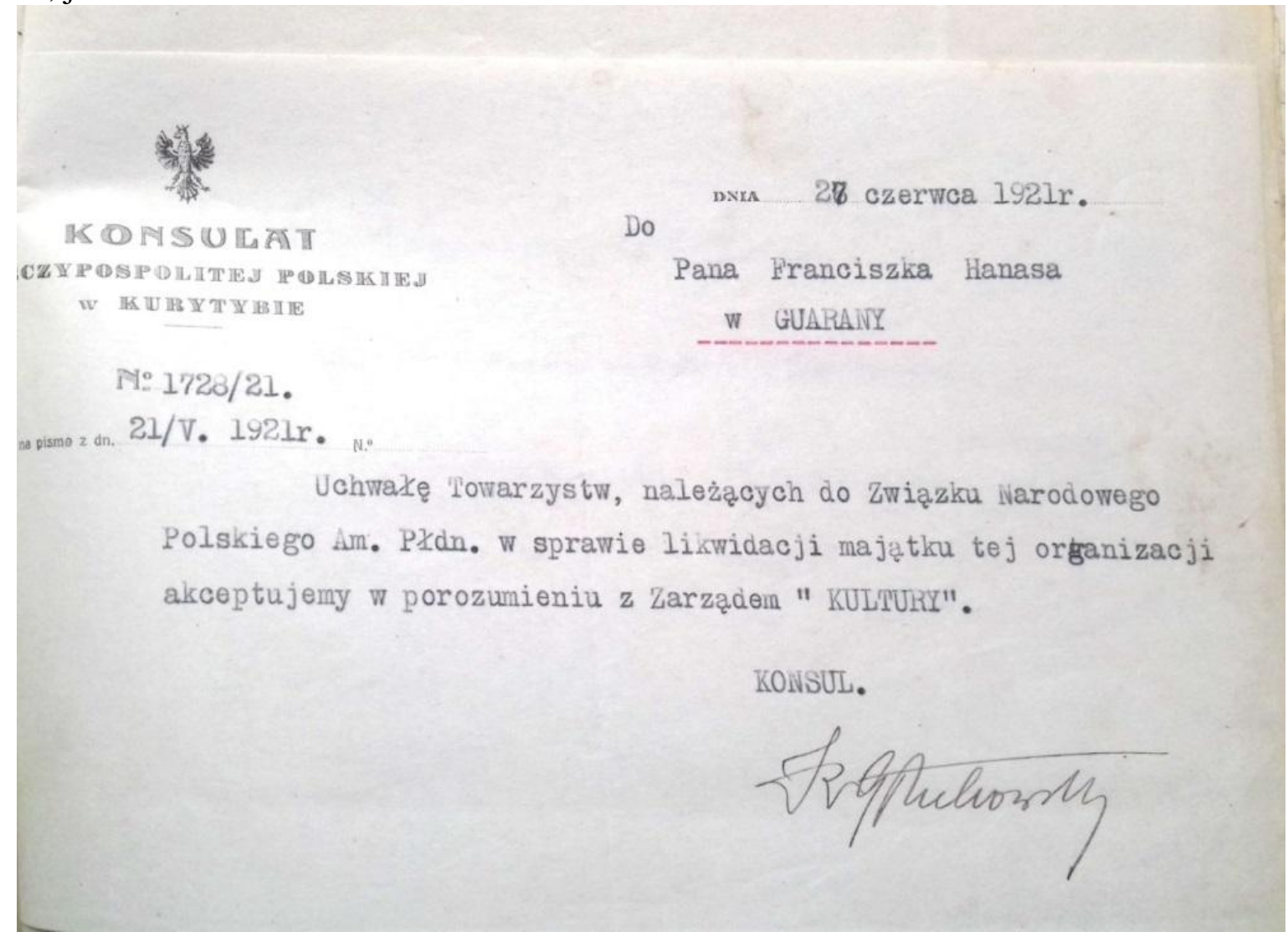

Fonte: Acervo dos Padres da Missão São Vicente de Paulo/Pasta Nacionalização (Curitiba $-\mathrm{PR})$.

Os agentes oficiais ligados à atuação consular visavam articular-se a discursos de polonidade e coesão nos processos de sociabilidade entre os migrantes (SILVA, 2019), urdindo estes a agentes e intelectuais étnicos e a imprensa étnica - embora não se possa afirmar um estrito alinhamento de discursos. Tais lideranças, em geral, buscavam artifícios para que cada vez mais as sociedades educacionais atuassem embasadas em percepções educacionais e culturais da Polônia e da educação polonesa, compartilhando intimamente com as pretensões da instância de orientação - Kultura. Já a Oświata, embora 
não se desapercebesse dos demais aspectos, voltava-se especialmente para os aspectos religiosos, parte da narrativa cultural da comunidade imaginada.

Aos poucos as necessidades educacionais estabeleceram laços de dependência bastante estreitos com as possibilidades de apoio do consulado e a Igreja, seja através de repasses de dinheiro e instrução pedagógica, seja através da facilitação da comunicação com a comunidade de saída e o fortalecimento da imprensa escolar étnica. Entretanto, a atuação de representantes do consulado nas sociabilidades e em especial nas sociedades educacionais, despertava diferentes opiniões entre os religiosos e a comunidade. Conforme afirmam Weber \& Zaleski Trindade (2016, p. 284-285), “a ligação de lideranças de imigrantes poloneses com o consulado teve efeito divergente". Enquanto alguns clérigos viam como importante e necessário o auxílio dado e a vinculação com as entidades na Europa, outros tinham preocupação com a ação dos agentes esquerdistas e professores progressistas, e as intencionalidades dos mesmos em relação às escolas e o afastamento da igreja.

Essa preocupação se fortaleceu com o retorno do cônsul Gluchowski para a Polônia e a chegada de um novo cônsul. A partir de então, o consulado colocou-se na tentativa de interferência ainda mais direta nos processos culturais e identitários, buscando frear possíveis processos de transformação cultural e desvinculações graduais da polonidade. Então, conforme Wachowicz (2010, p. 6-8), "Visando eliminar as rivalidades e as disputas entre os grupos, agora mais conhecidos por "Kultura" e "Oświata", sob o patrocínio do Consulado de Curitiba, surgiu em 1930 o "Centralny Związek Polaków" (União Central Polonesa)"; destaca que "Essa nova entidade tinha por objetivo básico centralizar e administrar todas as organizações polonesas no Brasil”, unificadas na CZP. Assim, "Tanto a "Kultura" como a "Oświata" dela passaram a fazer parte, mas, transcorridos dois anos, a "Oświata" com todas as suas organizações desfiliou-se e continuou sua trajetória própria" (WACHOWICZ, 2010, p. 8).

A atitude do novo cônsul também se voltava para fomentar as instituições existentes e seus meios de comunicação, bem como apoiar a criação de novas. Colocou-se centralizado em Curitiba, um espaço de acalorados embates entre as diferentes concepções, articuladas principalmente a CZP, o Conselho Geral das Sociedades Junak (Naczelna Rada Junacka) e a Associação Polonesa de Livre Pensamento (Polskie Stowarzyszenie Myśli Wolnej), entre outras. Porém, esse ambiente passou a ser menos apreciado pelos membros da Oświata, quando, conforme Weber (2015, p. 265): "Roman Staniewicz, cônsul entre 1932 e 1934, aderiu à ala anticlerical, acentuando antigas 
divergências, o que resultou no rompimento definitivo no âmbito da CZP (WACHOWICZ, MALCZEWSKI SChr, 2000: 360)”. Para a autora, “A jovem República Polonesa" "oscilava em sua política diplomática, e os representantes consulares, ao tomarem partido nas querelas das lideranças emigradas, enfraqueciam-se como agentes de promoção da identidade étnica".

A Oświata entendia que o posicionamento do novo cônsul acabou por favorecer a Kultura e era visto como prejudicial ao trabalho que vinham fazendo até então. Após sua fundação, a CZP passou a ajudar na manutenção das escolas filiadas, repassando-as a percentagem de ajuda. Conforme Malikoski (2014, p. 187), “a contribuição para a manutenção das escolas pelo CZP era de 12\%", então, "Todas as escolas da Kultura passaram a fazer parte do CZP, enquanto que as da Oświata permaneceram por um período breve, passando a funcionar novamente de forma independente". A contribuição era condicionada, e a Oświata demonstrava-se pouco disposta a aceitar a interferência direta, iniciando-se aí uma relação conflituosa.

Os conflitos se acirravam ainda mais com posturas da CZP à abertura e solicitação de colaborações por parte do estado do Paraná. Assim, a Oświata retira-se ressaltando seu desejo de permanecer autônoma e sem interferências ditas "externas", temerárias em relação ao prosseguimento de seu projeto de uma comunidade polonesa fortemente vinculada à religiosidade católica.

A articulação do consulado em relação às sociabilidades polonesas foi efetiva até 1937, porém, em 1938, o funcionamento destas, principalmente as escolares e instâncias de orientação, é duramente atingido com a política e o decreto de nacionalização e as ações restritivas em relação aos aspectos culturais étnicos e, logo em seguida, o corte nas relações devido ao início da Segunda Guerra Mundial e a invasão da Polônia pelas tropas alemãs. Com o início do conflito e a instalação do Governo polonês no Exílio, há de imediato, uma quebra no apoio da Polônia para com as sociedades na diáspora.

A política de nacionalização do Estado Novo e as restrições em relação aos processos culturais e identitários-étnicos dos imigrantes, significou o encolhimento e o fechamento das sociedades étnicas e escolares e da imprensa étnica, assim como, restringiu a ação do consulado. Já o conflito mundial representou dificuldades e a centralização no apoio às necessidades da Polônia em guerra. Apresentavam-se dificuldades de comunicação, rupturas no envio de professores, envio de descendentes para formação na Polônia, aportes financeiros, materiais didático-pedagógicos e funcionamento da imprensa. 
Isso tudo gerou um ambiente de ruptura, de contínua instabilidade, tensão e desarticulação, principalmente nas práticas educacionais escolares vinculadas ao projeto de imaginação, popularização das narrativas nacionais, retomada de heróis poloneses e construção do "espírito" nacional.

Dentre os heróis, estava o próprio Piłsudski, que buscava construir uma imagem populista, ressaltando seu papel na luta pela reunificação. Seu nome estava presente nas escolas e associações, inclusive naquelas da diáspora, em locais públicos e privados, presente entre adultos e crianças. O escritor Alfredo Sirkis (1983, p. 37), destaca essa presença populista e heroica na narrativa da garota brasileira Anna, filha do judeu-polonês Binek: "Quando eu tinha doze anos, dois fatos importantes marcaram minha vida: primeiro, o dia da morte do Mal. Pilsudski, chamado carinhosamente de Dziadeczek, "o vovozinho", alvo de uma verdadeira veneração por ter libertado a Polônia". As crianças tinham clara participação na reverberação de tais memórias e representações enquadradas.

Para Bourdieu (2007) a escola oferece itinerários - métodos e programas de pensamento, esquemas intelectuais e linguísticos balizam os sentidos e significados compartilhados nas práticas pedagógicas articulados com programas de ensino, literaturas, manuais. Bourdieu (2007, p. 206) ressalta ainda, que "a escola, incumbida de transmitir esta cultura, constitui o fator fundamental do consenso cultural nos termos de uma participação de um senso comum entendido como condição da comunicação". Por isso a escola polonesa ou a polska szkoła recebia olhares tão atentos, assim como, o trabalho do professor (religioso ou laico) foi visto como algo decisivo e vital, um agente cultural cuja atuação tinha que ser diferenciada, além de ensinar, precisava ser capaz de desempenhar um efetivo papel social. Assim, a formação de professores com um perfil claro, foi um dos objetivos tangenciados nos propósitos da intervenção consular.

Para Jorn Rüsen (2014), a cultura dá ao ser humano a possibilidade de atribuição de sentido para sua vida, para agir no mundo, orientar a práxis vital e motivar a vontade, para a forma como ele age ao lidar com a natureza e o mundo social. Então, os processos históricos resultam de diferentes sentidos que são colocados na práxis humana. Porém, a cultura não é estática e não se define a partir de quadros estáveis de significados, trata-se de algo dinâmico, que se transforma, uma vez em contato com novas realidades e possibilidades de significação, nas experiências individuais e coletivas, em situações de discursos e negociações em relações culturais e de poder, em trocas simbólicas. Assim, embora as sociabilidades estejam permeadas por uma proposta ou intencionalidade com pretensões homogeneizantes, considerando a dinâmica cultural, cada uma possui suas 
particularidades que estão ligadas a diversas questões, entre elas, o espaço, o meio onde estão localizadas - urbano ou rural, as relações interétnicas variadas ou limitadas, culturas e saberes escolares, entre outras questões.

De todo modo, a atuação consular mostrou-se efetiva, ampliou o diálogo e a coesão, foi propositiva e impositiva em distintas situações, fortaleceu o funcionamento e o desenvolvimento das sociabilidades, a circulação de representações e discursos nacionalistas, culturais e identitários, e esteve articulada a demandas tanto da Segunda República, quanto dos migrantes da diáspora. A atuação do consulado, as sociedades, os agentes e intelectuais étnicos e a imprensa polonesa, colocaram questões novas e fortaleceram algumas já existentes nestes cenários diaspóricos, muitas delas, atreladas ao contexto europeu anterior à migração e não tangenciadas de maneira tão contundente, até então. Em relação ao contexto brasileiro, por exemplo, debates sobre os movimentos operários, esquerdistas e inserção social das mulheres, posicionamentos nacionalistas e imaginação nacional e identitária.

\section{Considerações finais}

As sociabilidades e iniciativas educacionais comunitárias e confessionais étnicas, organizadas através de sociedades escolares e professores pagos pelos próprios migrantes se fizeram presentes entre os poloneses desde os primeiros anos da diáspora. Tais atitudes são tomadas por distintos grupos migrantes no Brasil dos séculos 19 e 20, na busca por reconstruir suas vidas e identidades nestes novos espaços sociais e na demanda por suprir carências da estrutura social e educacional do contexto brasileiro do período. No entanto, no pós-reunificação polonesa estas organizações étnicas passam a ser "vistas" de forma mais atenta por órgãos oficiais como o consulado, que, a partir da Segunda República e do propósito de construção de uma comunidade culturalmente imaginada e da expansão de colônias em terras ultramarinas, atua articulando-as em favorecimento de tais objetivos, na tentativa de alinhá-las principalmente à educação escolar em terras polacas.

Destacamos o papel dos agentes consulares e comunidade de saída, articulando-se a discursos nacionalistas e de polonidade, nestes processos educacionais, culturais e identitários, condução dos projetos acima mencionados e de expansão religiosa católica, econômica e política, intencionalidades voltadas tanto para a sociedade de inserção, 
quanto para a de origem. Tudo isso, na compreensão de que as sociabilidades e os espaços educacionais escolares étnicos dos migrantes, suas práticas pedagógicas e redes de articulação e estruturação, são efetivos lugares de permanente prática e práxis cultural e política, em uma compreensão mais ampla, amparada em embasamentos teóricometodológicos da História Cultural. Perceber as escolas e a educação através deste olhar permite renovar a compreensão dos processos históricos, da sociedade e dos exercícios de poder e participação. A educação pode ter sido vista como prioridade por seu potencial de inserção e cobertura de distintos campos do desenvolvimento humano e social, potencializando novas possibilidades aos seus emigrados nos novos lugares de acolhida e mantendo a vinculação cultural e identitária.

\section{Referências}

ANDERSON, B. Comunidades Imaginadas: reflexões sobre a origem e a expansão do nacionalismo. São Paulo, SP: Cia das Letras, 2008.

BAUMAN, Z. Identidade. Rio de Janeiro, RJ: Jorge Zahar Ed., 2005.

BARTH, F. Grupos étnicos e suas fronteiras [1969]. In: O guru, o iniciador e outras variações antropológicas. Rio de Janeiro, RJ: Contra Capa Livraria, 2000.

BURKE, P. O que é História Cultural? Trad. de Sergio Goes de Paula. 2 Ed. Rio de Janeiro, RJ: Zahar, 2008.

BOURDIEU, P. A economia das trocas simbólicas. São Paulo, SP: Ed. Perspectiva, 2007.

CHARTIER, R. A História Cultural: entre práticas e representações. $2^{\mathrm{a}}$ ed. Lisboa: DIFEL, 1989.

BRAINERD. M. D. Helena Radlinska Expanding conceptualizations of social work practice from Poland's past. International Social Work, Austrália. v. 44, n. 1, pp. 19-30. Jan. 2001.

CUCHE, D. A Noção de Cultura nas Ciências Sociais. Bauru, SP: EDUSC, 2002.

DELORY-MOMBERGER, C. Biografia e Educação: figuras do indivíduo-projeto. Trad. Maria da Conceição Passeggi, João Gomes da Silva Neto, Luis Passeggi. Natal, RN: EDUFRN; São Paulo, SP: Paulus, 2008.

FABRE, D. (Org.). Écritures ordinaires. Paris: Centre Georges Pompidou, Bibliothéque Publique d' Information, 1993.

FOUCAULT. M. Vigiar e punir: o nascimento da prisão. 36ª ed. Petrópolis, RJ: Vozes, 2009. 
GLUCHOWSKI, K. Os poloneses no Brasil: subsídios para o problema da colonização polonesa no Brasil. Tradução de Mariano Kawka. Porto Alegre, RS: Rodycz \&Ordanowski Editores, 2005.

HALL, S. Identidade cultural na pós-modernidade. Tradução: Tomaz Tadeu da Silva, Guacira Lopes Louro. 11 Edição. Rio de Janeiro, RJ: DP\&A, 2006.

HALL, S. Quem precisa de identidade? In: SILVA, Tadeu (org). Identidade e diferença: a perspectiva dos estudos culturais. $6^{\circ}$ edição. Petrópolis, RJ: Vozes, 2006. p 103-133.

HALL, S. Da Diáspora: Identidades e mediações culturais. Belo Horizonte, MG: UFMG, 2013.

HOBSBAWM, E. Nações e nacionalismo desde 1780: programa, mito e realidade. Rio de janeiro, RJ: Paz e Terra, 2011.

IOTTI, L. H. Imigração e Poder: A palavra oficial sobre os imigrantes italianos no Rio Grande do Sul (1875-1914). Caxias do Sul, RS: Educs, 2010.

KREUTZ, L. A Educação de Imigrantes no Brasil. In: 500 Anos de Educação no Brasil (Org. LOPES, Eliane Marta Teixeira; FILHO, Luciano Mendes de Faria;) 2. ed. Belo Horizonte, MG: Autêntica, 2000 a. p. 347-370.

LUCHESE, T. Â. As Escolas Étnico - Comunitárias Italianas no Rio Grande do Sul: $O$ olhar dos Cônsules e Agentes Consulares. In: LUCHESE. T. Â. \& KREUTZ, L. (Org.). Imigração e Educação no Brasil: Histórias, Práticas e Processos Escolares. Santa Maria, RS: Ed. UFSM, 2011.

MALIKOSKI, A. Escolas étnicas dos imigrantes poloneses no Rio Grande do Sul, (18751939). Dissertação de Mestrado. Universidade de Caxias do Sul, 2014.

LUCHESE, T. A; \& MALIKOSKI, A. O processo de organização de escolas étnicas polonesas no Rio Grande do Sul (1875-1939). Revista Brasileira de História da Educação, Maringá, PR, v. 17, n 46, pp. 99-119. Jul. 2017.

MALCZEWSKI, Z., \& WACHOWICZ, R. C. Perfis polônicos no Brasil. Curitiba, PR: Vicentina, 2000.

MALCZEWSKI, Z. SChr. Marcas da Presença polonesa no Brasil. Varsóvia: Instytut Studiów Iberyjskich i Iberoamerykańskich - Uniwersytetu Warszawskiego [Universidade de Varsóvia], 2008.

MAZUREK, J. A Polônia e seus Emigrados na América Latina (até 1939). Tradução de Mariano Kawka. Goiânia, GO: Editora Espaço Acadêmico, 2016.

OLIVEIRA, M. de. (2009, junho) Origens do Brasil meridional: dimensões da imigração polonesa no Paraná, 1871-1914. Revista Estudos Históricos, Rio de Janeiro: v. 22, n. 43, pp.218-237. Jan/Jun. 2009. 
RENK, V. E. As Escolas Étnicas Polonesas e Ucranianas no Paraná. Curitiba, PR: Appris, 2014.

RÜSEN, J. Cultura Faz Sentido: orientações entre o ontem e o amanhã. Petrópolis, RJ: Editora Vozes, 2014.

RÜSEN, J. Teoria da História: Uma teoria da história como ciência. Curitiba, PR: Editora UFPR, 2015.

SILVA, F. R. da. Associações polonesas união das sociedades Kultura e Oswiata (Curitiba -PR) - antagonismos e polonidade(s) na diáspora (1890-1939). Tese de Doutorado. Universidade Federal de Santa Maria, 2019.

SIRKIS, A. O Corredor Polonês. Rio de Janeiro, RJ: Record, 1983.

SIUDA-AMBROZIAK, R. Religião na construção da identidade étnica dos polonobrasileiros. In: Augusto, I. R; Dadalto, M. C; Siuda-Ambroziak, R. (Organizadoras) Subjetividades em trânsito: memória, emoção, e-imigração e identidades. - Macapá / Rio de Janeiro, RJ: UNIFAP / Bonecker, 2017.

TÖLÖLYAN, K. Estudos da diáspora: passado, presente e promessa. Revista Translatio: Tradução e Diásporas Negras, Porto Alegre, n. 13, pp. 22-39. Jun. 2017.

WACHOWICZ, R. C. “A Febre Brasileira na imigração polonesa”, em: Superintendência das Comemorações do Centenário da Imigração Polonesa no Paraná, Anais da comunidade brasileiro-polonesa. Curitiba, PR: Imprimax Ltda. vol. I. 1970.

WACHOWICZ, R. C. Aspectos políticos e ideológicos da imigração polonesa no Brasil (1869-1964). Blog Czytelnia Jezyk Portugalski (Leitura - Língua portuguesa). Disponível em:

http://googleweblight.com/?lite_url=http://czytelniabrasil.blogspot.com/2010/09/aspectos$\mathrm{r}$ wachowicz.html?m\%3D1\&ei $=0 \mathrm{qBpmR}-\mathrm{N} \& \mathrm{lc}=\mathrm{pt}$

BR\&s $=1 \& m=670 \&$ host $=w w w . g o o g l e . c o m . b r \& t s=1489755156 \&$ sig $=A J$ SQQ1BfCH0lvN2 62zDGFGKw UCrl28de\&lite_refresh=1548724658721._Acesso em Ago. 2018.

WEBER, R. Agentes e intelectuais étnicos entre os poloneses. Revista Tempos Históricos, Marechal Cândido Rondon: Unioeste, vol. 19, n. 1, pp. 253-273. Ago. 2015.

WEBER, R; \& ZALESKI TRINDADE, R. T. Imigrantes poloneses no Brasil no contexto da dominação austríaca. Revista del CESLA. Varsóvia, Polonia: Uniwersytet Warszawski, n. 19, pp. 269-289. Nov. 2016.

Submetido em: 01/08/2020

Aprovado em: 20/08/2020

Publicado: 23/09/2020

\footnotetext{
${ }^{\text {i }}$ Doutora em História pela Universidade Federal de Santa Maria. Possui mestrado em Educação pela mesma instituição. E-mail: fabianareginadasilva@yahoo.com.br
} 
${ }^{i i}$ Silva (2019) trata a situação migratória dos poloneses nos séculos 19 e 20 como diáspora. Tal posicionamento ocorre a partir das teorias contemporâneas da diáspora - um passo à frente da clássica diáspora judaica, dos estudos culturais e de questões evidenciadas a partir da historiografia e das questões levantadas pela pesquisa, ressaltando características diaspóricas, entre elas: a dispersão, a relação com a terra de origem e com migrantes em outros estados, as vivências traumáticas e as memórias compartilhadas, as atitudes associativas e de relação com outros membros da diáspora e a comunidade cultural imaginada na dispersão - traços culturais diferenciadores (Hall, 2013), "autorrepresentação continuada e a perpetuação de diferenças significativas" (Tölölyan, 2007, p. 649) e as polonidades, para a autora há a qualidade de ser polonês que eles compartilham com outros migrantes.

iii Entre as fontes analisadas pela pesquisadora em sua Tese de doutorado defendida em 2019 no Programa de Pós-Graduação em História da UFSM, estão documentos públicos e privados do Arquivo dos Padres da Congregação da Missão de São Vicente de Paulo, em Curitiba - PR e também, do Acervo da Sociedade Polônia em Porto Alegre - RS.

${ }^{\text {iv }}$ Para o teórico da história, Jorn Rüsen (2015, p. 66), de forma mais restritiva, este significado só pode ser vestido, "quando se trate, efetivamente, de constatar controlavelmente, mediante processo metódico (de pesquisa) a facticidade dos acontecimentos no passado", como prática da intersubjetividade, ou seja, "trata-se de apresentar (narrar) as sentenças históricas (histórias) de maneira que se possa, genericamente, concordar com elas".

v Os migrantes poloneses tiveram distintos locais de saída em uma Polônia dividida e inexistente como unidade política e geográfica de Estado, assim, ao emigrar, portavam documentos de origem prussiana, austríaca e russa.

${ }^{v i}$ Anotações de Ruy C. Wachowicz, encontradas na pasta Wachowicz, no Acervo dos Padres da Missão São Vicente de Paulo - Curitiba-PR.

vii Anais da Comunidade Brasileiro-Polonesa/1970/Volume II.

viii Idem nota V.

${ }^{\text {ix }}$ Nascido na Polônia, na região de domínio prussiano, formou-se músico e professor. Sobre a vida de Jerônimo Durski, além de outros materiais impressos e digitais, o vídeo "O Dono da Rua" de 2009 traz um apanhado importante sobre o personagem e a fala do Pe. Lourenço Bienarski (Congregação da Missão) em uma análise sobre seus diários e sua atuação docente e articulada na etnicidade. Disponível em https://www.youtube.com/watch?v=16PvFe7XtaE. Acesso em: 22 jun. 2018.

${ }^{\mathrm{x}}$ Ibidem nota V.

${ }^{x i}$ Ao tratar sobre as categorias, Weber (2015, p. 253-254) destaca "diferentes modos de ação étnica" e a presença de "agentes étnicos" e "intelectuais étnicos" no Brasil entre o final do século XIX e primeira metade do século XX, dentre estes, estão representantes de "instituição religiosa (os Vicentinos)" e de instituições estatais (representantes consulares). A autora toma o conceito de intelectual étnico a partir de Gimenez (1997, p. 14), o qual destaca que: "Reunindo contribuições de diferentes vertentes, pode-se pensar nos intelectuais étnicos como indivíduos engajados na formulação e transmissão de representações".

xii Sociedade Geográfica e Comercial com sede em Lwów, na parte austríaca - era o órgão responsável pela emigração polonesa para a América Latina. Por ter maior autonomia em relação aos domínios da Rússia e da Prússia, a região contava com sociedades comerciais, científicas e movimentos populares e sindicais.

xiii Conceito apropriado por Michel Foucault (2009) na obra Vigiar e Punir, tratando de mecanismos adotados pelas instituições em suas arquiteturas institucionais, voltados para a vigilância e normalização dos sujeitos.

${ }^{\text {xiv }}$ O autor nasceu em 1925, filho de uma família judia polonesa. Durante a Segunda Guerra Mundial enfrentou o nazismo como participante do exército polonês aliado ao Exército Vermelho. Na Polônia enfrentou o antissemitismo e o Partido Comunista como repressor dos movimentos dos estudantes poloneses, como resultado, em 1968 teve seus trabalhos proibidos de publicação, seu cargo de professor destituído e foi expulso da Polônia e destituído oficialmente de sua cidadania, mudando-se para a Inglaterra. A obra deste autor, aqui citada, com o título "Identidade", compõe-se de alguns trechos de narrativas autobiográficas.

${ }^{x v}$ As uniões de sociedades Kultura e Oświata - sediadas em Curitiba - PR e as polonidade (s) são as interfaces de pesquisa fundamentais trabalhadas pela autora Silva (2019) em sua tese de doutorado. 